\title{
El procedimiento arbitral para resolver las reclamaciones en las elecciones a órganos de representación del personal al servicio de las Administraciones Públicas
}

\section{Arbitration proceeding to resolve claims on elections to representative bodies for public employees}

\author{
Ángel Luis de Val Tena \\ Universidad de Zaragoza (España) \\ ORCID: http://orcid.org/0000-0003-3276-5983 \\ adeval@unizar.es
}

\begin{abstract}
NOTA BIOGRÁFICA
Licenciado y Doctor en Derecho, con premio extraordinario, por la Universidad de Zaragoza. Profesor Titular Catedrático de Derecho del Trabajo y de la Seguridad Social. Principales líneas de investigación: contrato de trabajo, relaciones laborales especiales, representación de los trabajadores, negociación colectiva, Seguridad Social, prevención de riesgos laborales, empleo, solución de conflictos.
\end{abstract}

\section{RESUMEN}

Los órganos de representación de los empleados públicos se seleccionan a través de un procedimiento electoral. Las impugnaciones en materia electoral se tramitan conforme a un procedimiento arbitral, salvo las denegaciones de inscripción de las actas electorales, cuyas reclamaciones podrán plantearse directamente ante la jurisdicción competente. El laudo será escrito y razonado, resolviendo en derecho sobre la impugnación del proceso electoral. Además, el laudo arbitral podrá impugnarse ante el orden social de la jurisdicción mediante la modalidad procesal correspondiente.

\section{PALABRAS CLAVE}

Órganos de representación; elecciones sindicales; reclamaciones en materia electoral; laudo arbitral; impugnación judicial.

\begin{abstract}
Representative bodies for public employees are selected through an electoral procedure. Challenges on electoral matters shall be processed in accordance with an arbitration proceeding, except for refusals to register electoral records, whose claims may be directly formulated before the competent jurisdiction. The arbitration ruling shall be written and justified, and shall rule by law on the challenge to the electoral process. Moreover, the arbitration award may be challenged before the Labour Courts through the relevant procedural methods.
\end{abstract}

\section{KEYWORDS}

Representative bodies; union elections; complaints on electoral matters; arbitration award; judicial challenge. 


\begin{abstract}
SUMARIO
1. INTRODUCCIÓN: SOBRE LA ELECCIÓN DE LOS ÓRGANOS DE REPRESENTACIÓN DEL PERSONAL AL SERVICIO DE LAS ADMINISTRACIONES PÚBLICAS. 2. RECLAMACIONES EN MATERIA ELECTORAL. 2.1. LA SEGMENTACIÓN DEL SISTEMA DE IMPUGNACIÓN: RECLAMACIONES ARBITRALES VS. RECLAMACIONES ANTE LA JURISDICCIÓN SOCIAL. 2.2. LAS IMPUGNACIONES ELECTORALES A TRAVÉS DEL PROCEDIMIENTO ARBITRAL. 2.2.1. Caracterización del arbitraje: obligatorio, legal y de derecho. 2.2.2. Ámbitos subjetivo y objetivo. 2.2.3. Iniciación, desarrollo y finalización: del escrito de impugnación al laudo arbitral. 2.3. LA IMPUGNACIÓN JUDICIAL DE LOS LAUDOS ARBITRALES. 3. A MODO DE CONCLUSIÓN: TRANSCENDENCIA DEL PROCESO ELECTORAL Y RESOLUCIÓN EXTRAJUDICIAL DE LOS CONFLICTOS JURÍDICOS. REFERENCIAS BIBLIOGRÁFICAS.
\end{abstract}

\title{
1. INTRODUCCIÓN: SOBRE LA ELECCIÓN DE LOS ÓRGANOS DE REPRESENTACIÓN DEL PERSONAL AL SERVICIO DE LAS ADMINISTRACIONES PÚBLICAS
}

Con carácter general, se reconoce ex lege que los empleados públicos tienen «derecho a la negociación colectiva, representación y participación institucional para la determinación de sus condiciones de trabajo» (art. 31.1 TREBEP), entendiéndose por representación «la facultad de elegir representantes y constituir órganos unitarios a través de los cuales se instrumente la interlocución entre las Administraciones Públicas y sus empleados» (art. 31.3 TREBEP). Así, por una parte, la representación de los empleados públicos con contrato laboral se rige por la legislación laboral (art. 32.1 TREBEP), articulándose la representación unitaria mediante la elección de delegados de personal y comités de empresa ${ }^{1}$, cuya regulación específica se encuentra en el vigente texto refundido de la Ley del Estatuto de los Trabajadores ${ }^{2}$ (en adelante, TRLET). Por otra, los órganos específicos de representación de los funcionarios y del personal estatutario son los delegados de personal y las juntas de personal, elegidos conforme a lo establecido en el texto refundido de la Ley del Estatuto Básico del Empelado público ${ }^{3}$ (en adelante, TREBEP) y, transitoriamente ${ }^{4}$, en los preceptos no derogados de la Ley 9/1987, de 12 de junio, de órganos de representación, determinación de las condiciones de trabajo y participación del personal al servicio de las Administraciones Públicas, que se mantienen aplicables con carácter de normativa básica en tanto se determine el procedimiento electoral general previsto en el artículo 39 TREBEP.

Estos órganos de representación unitaria de los empleados públicos tienen en común, ya representen a trabajadores, ya representen a funcionarios o personal estatutario, que son elegidos diferenciadamente por dichos colectivos, según la composición y dimensión de la plantilla que conforme la unidad electoral. Al margen de otras cuestiones de interés, como las relativas al funcionamiento de los órganos de representación, a las funciones y garantías de los representantes legales o unitarios o a la duración de su mandato, el legislador regula de forma expresa la promoción de elecciones y el desarrollo del procedimiento electoral, y lo hace separadamente, en diferentes textos legales y normas reglamentarias, si bien con muchos puntos en común.

En efecto, los preceptos legales que contiene el Estatuto de los Trabajadores fueron desarrollados por el RD 1844/1994, de 9 de septiembre, que aprueba el Reglamento de elecciones a órganos de representación de los trabajadores en la empresa, mientras que los artículos de la Ley 9/1987-y, ahora, del vigente

\footnotetext{
1 Esos órganos de representación unitaria conviven con la representación sindical que pudiera existir en la misma, sin que ambos modelos se excluyan, pudiendo coexistir; estamos en presencia, por tanto, de lo que se ha llamado un «doble canal de representación», puesto que junto a los delegados de personal y comités de empresa -canal unitario-, la legislación vigente permite la presencia de secciones y delegados sindicales - canal sindical-.

2 Cfr. Artículos 62 y 63 del RD-Leg. 2/2015, de 23 de octubre, que aprueba el texto refundido de la Ley del Estatuto de los Trabajadores.

3 Cfr. Artículo 39 del RD-Leg. 5/2015, de 30 de octubre, por el que se aprueba el texto refundido de la Ley del Estatuto Básico del Empleado Público.

4 Téngase en cuenta que la disposición transitoria quinta, primero, de la Ley 7/2007, de 12 de abril, del Estatuto Básico del Empleado Público y, después, del RD-Leg. 5/2015, de 30 de octubre, que aprueba el texto refundido de la Ley del Estatuto Básico del Empleado Público, derogó la Ley 9/1987, de 12 de junio, de Órganos de Representación, Determinación de las Condiciones de Trabajo y Participación del Personal al Servicio de las Administraciones Públicas, excepto su artículo 7, y estableció, no obstante, que «en tanto se determine el procedimiento electoral general previsto en el artículo 39 del presente Estatuto, se mantendrán con carácter de normativa básica los siguientes artículos de la Ley 9/1987, de 12 de junio, de órganos de representación, determinación de las condiciones de trabajo y participación del personal al servicio de las Administraciones Públicas: 13.2, 13.3, 13.4, 13.5, 13.6, 15, 16, 17, 18, 19, 20, $21,25,26,27,28$ у $29 . »$.
} 
Estatuto Básico del Empleado Público- fueron desarrollados por el RD 1846/1994, de 9 de septiembre, que aprueba el Reglamento de elecciones a órganos de representación del personal al servicio de la Administración General del Estado. Más allá de la coincidencia en la fecha y parcialmente en su denominación, ambos reglamentos tienen su origen en la leyes de reforma que se aprobaron el año 1994.

Una, la Ley 11/1994, de 19 de mayo, por la que se modificaron determinados artículos de la Ley 8/1980, de 10 de marzo, del Estatuto de los Trabajadores, del Texto Articulado de la Ley de Procedimiento Laboral y de la Ley sobre Infracciones y Sanciones en el Orden Social, vigentes en aquella fecha; concretamente, interesa destacar algunas novedades importantes, como la nueva redacción de los artículos dedicados a la promoción de elecciones, a la celebración de estas o a las funciones de la mesa electoral, al mismo tiempo que se creaban nuevas figuras e instituciones jurídicas, como la Oficina Pública de registro de actas o el procedimiento de reclamaciones en materia electoral, en el que se sustituye la actuación de órganos tripartitos por un sistema arbitral obligatorio.

Otra, la Ley 18/1994, de 30 de junio, que procedió a la adecuación de la -entonces en vigor- Ley 9/1987 al nuevo sistema electoral, «toda vez que la elección de los representantes de los funcionarios públicos no debe constituir un régimen jurídico diferenciado respecto de otros trabajadores, manteniendo, no obstante, las mínimas diferencias que se derivan de las peculiaridades específicas de las personas jurídicas públicas» ${ }^{5}$. Al respecto, implantó un sistema de medición continuada de la representatividad, la celebración de elecciones conforme caducaran los mandatos representativos y la acreditación de dicha representatividad en el momento de ejercer tales funciones, eliminándose con ello la necesidad de una proclamación global de resultados; simplificó el sistema de cómputo de los resultados electorales y atribuyó a la Oficina Pública de registro las funciones propiamente registrales y de cómputo; y reguló un modelo de solución de conflictos de carácter arbitral, remitiendo, en última instancia, las controversias en materia de elecciones sindicales a la jurisdicción social.

Precisamente, el objeto de estudio del presente trabajo va a ser el procedimiento arbitral que se impone como obligatorio para resolver las reclamaciones o impugnaciones en materia electoral, de manera singular en las elecciones a órganos de representación del personal vinculado a una Administración Pública, tanto a través de una relación laboral como mediante una relación de carácter administrativo o estatutario. Los procedimientos de impugnación y control del conjunto de actuaciones que se desarrollan desde la promoción de las elecciones, durante el iter electoral y hasta la atribución de los resultados, y en concreto la identificación de materias conflictivas que han de seguir el procedimiento arbitral obligatorio instaurado, con todo su desarrollo, así como la actuación revisora del orden social de la jurisdicción, se exponen y analizan a continuación.

\section{RECLAMACIONES EN MATERIA ELECTORAL}

\subsection{La segmentación del sistema de impugnación: reclamaciones arbitrales vs. reclamaciones ante la jurisdicción social}

Los cambios introducidos, que afectaron al control de validez del procedimiento electoral para determinar la composición de los órganos de representación unitaria fueron, sin duda, transcendentes y supusieron, en realidad, una nueva regulación, más que una simple reforma o modificación de la normativa precedente (RUIZ MORENO, 1994: 711, y ESCUDERO RODRÍGUEZ, 1995: 517). Ese marco jurídico se ha consolidado y sigue hoy vigente, de manera que las impugnaciones en materia electoral se deben tramitar conforme al procedimiento arbitral regulado en el artículo 76 TRLET, cuando se elijen órganos de representación de los trabajadores, y en los artículos 44 TREBEP y 28 y 29 Ley 9/1987, si la elección es para escoger a los representantes de los funcionarios, con excepción de las denegaciones de inscripción de las actas electorales, cuyas reclamaciones se pueden plantear directamente ante la jurisdicción social, que es la competente [art. 2.i) LRJS], también cuando se trate de elecciones a órganos de representación del personal al servicio de las Administraciones Públicas. Procedimientos arbitrales, y así debe subrayarse ab initio, que apenas presentan diferencias.

5 Cfr. Exposición de Motivos de la Ley 18/1994, de 30 de junio, por la que se modifica la normativa de elecciones a los órganos de representación del personal al servicio de las Administraciones públicas de la Ley 9/1987, de 12 de junio, modificada por la Ley 7/1990, de 19 de julio. 
Si con anterioridad la reclamaciones en materia electoral se planteaban directamente ante los órganos del orden social de la jurisdicción por quienes tenían un interés directo en el proceso electoral de referencia ${ }^{6}$, sin otro trámite previo que la preceptiva reclamación ante la Mesa Electoral, la nueva regulación del procedimiento electoral instituye una primera instancia arbitral para las reclamaciones relativas a la elección, así como respecto de las decisiones de la Mesa Electoral, que finaliza con un laudo arbitral, pudiendo ser impugnado ante el órgano judicial a través de la modalidad procesal correspondiente (arts. 76.6 in fine TRLET y 29.3 in fine Ley 9/1987). Solo se excluyen ${ }^{7}$ del sistema arbitral previo las impugnaciones de las resoluciones administrativas que denieguen el registro de las actas de la elección [arts. 76.1 TRLET y 44.f) TREBEP].

Las modificaciones sobre el control de validez de los procesos electorales en las leyes sustantivas acarrearon, en paralelo, cambios en la modalidad procesal especial en materia electoral, observándose un efecto reflejo, pues exigió adaptar lo adjetivo o procesal a lo sustantivo. Las innovaciones, que interesa desatacar, consistieron: primero, en la creación de una Oficina Pública dependiente de la Autoridad laboral, encargada del registro de las actas de electorales ${ }^{8}$, siendo recurribles sus decisiones denegatorias ante el Juzgado de lo Social, conforme a la modalidad procesal reseñada en los artículos 133 a 136 de la -entonces vigente- Ley de Procedimiento Laboral (hoy, arts. 133 a 136 LRJS); segundo, el establecimiento, ya mencionado, de un procedimiento arbitral obligatorio para la solución del resto de impugnaciones, que concluye con un laudo, pudiéndose impugnar a través del procedimiento especial establecido en los artículos 127 a 132 de la -vigente en aquel tiempo- Ley de Procedimiento Laboral (actualmente, arts. 127 a 132 LRJS).

\subsection{Las impugnaciones electorales a través del procedimiento arbitral}

\subsubsection{Caracterización del arbitraje: legal, obligatorio y de derecho}

El legislador, en los artículos 76 TRLET y 46.f) TREBEB -de redacción, en esencia, coincidente- dispone que las impugnaciones en materia electoral se tramitarán conforme al procedimiento arbitral que se regula, sin perjuicio de que el laudo arbitral que ponga fin al procedimiento seguido pueda impugnarse ante el orden jurisdiccional social, a través de la modalidad procesal correspondiente. Se establece, así, un arbitraje obligatorio al que se someten las cuestiones litigiosas surgidas a lo largo del proceso electoral hasta la votación, cuyo desarrollo y resultado se refleja en las actas, con la sola excepción de las reclamaciones que versen sobre las denegaciones de inscripción de dichas actas electorales, que se pueden plantear directamente ante los órganos de la jurisdicción competente.

El procedimiento arbitral diseñado para canalizar las reclamaciones en materia electoral se caracteriza por ser un arbitraje laboral específico, colectivo, legal y obligatorio (CASAS BAAMONDE, 1994: 11), ajeno a la autonomía de las partes, al no haber sido pactado individual o colectivamente (LÓPEZ FERNÁNDEZ, 1994: 568), que plantea dudas de índole constitucional. Se ha cuestionado, sobre todo, la acomodación de esta instancia al artículo $117.3 \mathrm{CE}^{9}$ ya que «no se regula una vía previa, seguida de demanda ante el órgano jurisdiccional, sino un cauce único que supone el sometimiento de cuestiones litigiosas a órganos no judiciales, con la grave limitación del conocimiento judicial derivada de la naturaleza extraordinaria del recurso contra el laudo, cuyos motivos y contenido (los del recurso) están tasados en la ordenación del mismo» (MARíN CORREA, 1995: 171). Sin embargo, lo cierto es que la figura del arbitraje obligatorio ex lege aparece como un requisito previo a la vía judicial (BLASCO PELLICER, 1994: 92), y ello porque los motivos que facultan a aquellos que tengan interés legítimo para impugnar el laudo arbitral son tan amplios, sobre todo el recogido

6 Por el proceso especial regulado en los artículos 127 a 136 TALPL, se tramitaban las impugnaciones de los procedimientos en materia electoral, y las demás cuestiones relativas a la representación de los trabajadores podían ser objeto de un proceso ordinario o de conflicto colectivo cuando la pretensión no se ajustaba a este proceso especial (BAYLOS GRAU, CRUZ VILLALÓN, FERNÁNDEZ LÓPEZ, 1991: 263).

7 Así debe entenderse, según el tenor literal de los artículos 76.1 TRLET y 44.f) TREBEP, pues este último ya no reproduce el mismo tenor del artículo 28.1 Ley $9 / 1987$, que establecía una excepción al deber de seguir el procedimiento arbitral aquellas reclamaciones contra las denegaciones de inscripción de las actas electorales, puesto que frente a esas denegaciones -así se decía- «podrá optarse entre la promoción de dicho arbitraje o el planteamiento de la impugnación ante la jurisdicción social».

8 De conformidad con los artículos 75.7 TRLET y 27.2 Ley 9/1987, corresponde a la Oficina Pública dependiente de la Autoridad laboral el registro de las actas, así como la expedición de copias auténticas de las mismas y, a requerimiento del sindicato interesado, de las certificaciones acreditativas de su capacidad representativa.

9 El artículo 117.3 CE dispone que «el ejercicio de la potestad jurisdiccional en todo tipo de procesos, juzgando y haciendo ejecutar lo juzgado, corresponde exclusivamente a los Juzgados y Tribunales determinados por las leyes, según las normas de competencia y procedimiento que las mismas establezcan». 
en el artículo 128.a) $\operatorname{LRJS}^{10}$, que de facto se crea una segunda instancia en materia electoral de carácter exclusivamente jurisdiccional, que puede significar una auténtica revisión del laudo, «lo que ataca la propia significación y eficacia del laudo» (FALGUERA BARÓ, 1994: 328). De esta manera, también se respeta el derecho a la tutela judicial reconocido en el artículo 24.1 CE, en cuanto que el laudo puede impugnarse, prácticamente sin limitación alguna, ante el orden jurisdiccional social, a través de la modalidad procesal señalada (artículo 76.6 TRLET). De esta manera, queda salvaguardado el derecho de las partes a acceder al órgano judicial competente para revisar los efectos del laudo arbitral.

\subsection{2. Ámbitos subjetivo y objetivo}

Mediante el procedimiento arbitral, de obligada tramitación como se ha señalado, se resuelven todas las reclamaciones relativas al proceso electoral, con excepción de las ocasionadas por la denegación del registro de actas electorales decidida por la Oficina Pública, que podrán tramitarse directamente ante la jurisdicción social.

El arbitraje puede plantearse por todos los que tengan interés legítimo -incluida la parte empleadorapara impugnar la elección, las decisiones de la Mesa o cualquier otra actuación de la misma a lo largo del proceso electoral (arts. 76.2 TRLET y 28.2 Ley 9/1987). Solo si se impugnan actos de la Mesa Electoral, para ejercer la acción impugnatoria se exige la reclamación previa ante la Mesa Electoral por el interesado, en un proceso electoral, dentro del día siguiente hábil al acto objeto de impugnación (arts. 76.2 TRLET) o, en otro, dentro del día laborable siguiente al acto de la votación (art. 28.2 Ley 9/1987). Diferencia el legislador según se trate de procesos electorales para elegir representantes de los trabajadores o de los funcionarios, si bien carece de sentido tener que esperar a la conclusión del acto de la votación, en el segundo supuesto, siendo más lógico poder impugnar de inmediato toda actuación de la Mesa Electoral, para dejar resuelta cualquier incidencia que más tarde puede hacer retrotraer o repetir el proceso electoral.

El ámbito objetivo o material del arbitraje viene concretado por la Ley cuando alude, expresamente, a que se podrán impugnar la elección, las decisiones de las Mesa Electorales, así como cualquier otra actuación de las mismas a lo largo del proceso electoral. Su competencia queda restringida, a priori, a las actuaciones de la Mesa a lo largo del proceso electoral, pues no debemos olvidar que dicho proceso se inicia con la constitución de la Mesa o Mesas Electorales el día fijado en el preaviso (arts. 67.1 y 74.1 TRLET y arts. 13.2 y 26.1 Ley 9/1987). De mantener esta inicial postura restrictiva quedarían excluidas todas aquellas cuestiones surgidas con anterioridad a la constitución de la Mesa, como serían la ordenación y convocatoria de las elecciones. Antes de la reforma de 1994, cuando la vía de impugnación no era la arbitral sino la judicial a través de un procedimiento especial, se tramitaban únicamente mediante este último los actos que surgían durante el proceso electoral, es decir, desde la constitución de la Mesa hasta la publicación de resultados y proclamación de candidatos (BAYLOS GRAU, CRUZ VILLALÓN, FERNÁNDEZ LÓPEZ, 1991: 264, y ALONSO OLEA; ALONSO GARCÍA, 2010: 287).

Con todo, el ámbito objetivo del arbitraje se configura no solo con la impugnación de los actos nacidos de la Mesa Electoral, sino también con los «actos de otras personas que inciden en el proceso afectando la licitud del mismo y que, en la mayoría de los casos, se traducirán también en actos de la Mesa que los acepta o convalida» (MATÍA PRIM, 1994: 237).

Esta conclusión, en principio contraria al tenor literal de la Ley, puede fundamentarse, en primer lugar, en la propia intencionalidad del legislador que ha querido que las impugnaciones en materia electoral se tramiten conforme al procedimiento arbitral previsto en los artículos 76 TRLET y 28 Ley 9/1987, con una única salvedad -denegación del registro de las actas electorales- ya reseñada.

Además, en segundo lugar, porque estos actos previos a la constitución de la Mesa Electoral, y no procedentes directamente de la actuación de ella misma, son presupuestos necesarios e imprescindibles para que se inicie el procedimiento electoral legalmente previsto. No puede pensarse en una elección a delegados de personal, miembros del comité de empresa u órganos correspondientes de las Administraciones

10 Artículo 128 LRJS: «La demanda solo podrá fundarse en:

a) Indebida apreciación o no apreciación de cualquiera de las causas contempladas en el artículo 76.2 del Estatuto de los Trabajadores, siempre que la misma haya sido alegada por el promotor en el curso del arbitraje.

b) Haber resuelto el laudo aspectos no sometidos al arbitraje o que, de haberlo sido, no puedan ser objeto del mismo.

c) Promover el arbitraje fuera de los plazos estipulados en el artículo 76 del Estatuto de los Trabajadores.

d) No haber concedido el árbitro a las partes la oportunidad de ser oídas o de presentar pruebas.». 
públicas sin la comunicación inicial de promoción de elecciones, máxime si tenemos en cuenta que en esta se identificará con precisión la empresa y el centro de trabajo o la unidad electoral en que se desea celebrar el proceso electoral y la fecha del inicio de este, que será la de constitución de la Mesa Electoral, y que el incumplimiento de cualquiera de los requisitos que debe reunir el preaviso determinará la falta de validez 0 nulidad del correspondiente proceso electoral (arts. 67.2 TRLET y 13.6 Ley 9/1987).

Por último, corrobora la tesis ampliatoria de las materias que pueden ser conocidas por el procedimiento arbitral los motivos que necesariamente han de fundamentar la impugnación: la existencia de vicios graves que puedan afectar a las garantías del proceso electoral y que alteren sus resultados, así como la falta de capacidad o legitimidad de los candidatos elegidos, la discordancia entre el acta y el desarrollo del proceso electoral o la falta de correlación entre el número de trabajadores o funcionarios que figuran en el acta de elecciones y el número de representantes elegidos (arts. 76.2 TRLET y 28.2 Ley 9/1987). El primer motivo enumerado -la existencia de vicios graves- permite acoger todas aquellas cuestiones conflictivas previas que condicionan ab initio el desarrollo del proceso electoral y que propiamente no son actos o decisiones de la Mesa Electoral, aunque indirectamente esta los acepte o convalide.

Contrariamente, la jurisprudencia sostuvo que el preaviso quedaba excluido del procedimiento arbitral en materia electoral, por lo que su impugnación debía presentarse directamente ante la jurisdicción social ${ }^{11}$, bien por el procedimiento ordinario, bien por el procedimiento de conflicto colectivo (CABEZA PEREIRO, 2009: 10-13), o incluso por el de tutela de los derechos fundamentales, al considerar la promoción de elecciones sindicales como parte del contenido adicional de derecho de libertad sindical. Por ello fue precisa la intervención del legislador (MEJÍAS, 2016: 598-600) para, superando finalmente aquella interpretación jurisprudencial, resolver que «se someterán a dicho arbitraje todas las impugnaciones relativas al proceso electoral desde la promoción de las elecciones, incluida la validez de la comunicación a la oficina pública del propósito de celebrar las mismas, así como todas las actuaciones electorales previas y posteriores a la constitución de la Mesa Electoral y las decisiones de esta, y la atribución de los resultados, hasta la entrada de las actas en la oficina pública dependiente de la autoridad administrativa o laboral».

Se logra así llevar al procedimiento arbitral todas las cuestiones conflictivas en materia electoral, desde la primera hasta la última actuación, ya se realice por una parte legitimada para promover la elección o por quienes participan o se ven concernidos por el proceso electoral, incluida la empresa o Administración Pública empleadora, ya por las Mesas Electorales, hasta la recepción de las actas electorales en la Oficina Pública competente para su registro. Lógicamente, como se altera el marco normativo que había permitido al Tribunal Supremo excluir las impugnaciones del preaviso de elecciones del cauce procedimental específico, ahora resulta obligado someter a arbitraje cualquier impugnación de un preaviso ${ }^{12}$.

De la redacción de los artículos 76.1 TRLET y 44.f) TREBEP cabe plantearse si las denegaciones de inscripción de las actas electorales pueden tramitarse también a través del procedimiento arbitral previo, antes de acudir al proceso laboral especial previsto en los artículos 133 a 136 LRJS. El legislador, como venimos señalado, permite acudir directamente ante la jurisdicción competente cuando se trate de reclamaciones por denegación de inscripción. En consecuencia, cualquier parte legitimada que entienda indebida la resolución positiva de la Oficina Pública de registrar los resultados no puede acudir directamente a la vía jurisdiccional, sino que debe agotar primeramente la vía arbitral, extendiéndose así el ámbito del arbitraje a una actuación administrativa (MARÍN CORREA, 1995: 171). En caso contrario, el de denegación de registro, la duda se plantea por el tenor literal que el legislador ha utilizado - «podrán plantearse directamente ante la jurisdicción competente»-, en el sentido de si debe permitirse a las partes afectadas por la denegación, a decisión de ellas, que acudan con carácter previo al procedimiento arbitral para resolver la correcta o incorrecta denegación de la inscripción, esto es, el carácter potestativo de la impugnación arbitral.

Aunque ha existido alguna toma de postura doctrinal a favor de que la demanda directa ante la jurisdicción social en los casos de denegación de registro es optativa (MONGE RECALDE, 1994: 153), parece que tal alternativa no cabe, pese a la expresión verbal equívoca, ya que del contexto se sigue que el término «podrán» ha de interpretarse como facultad de demandar y no como fórmula disyuntiva que queda a la voluntad del interesado, y, sobre todo, porque la intervención de la Oficina Pública encargada del registro, con el consiguiente plazo de subsanación de defectos de las actas en caso de observarse alguno (10 días, según

\footnotetext{
11 SSTS de 4 de mayo de 2006 (Rec. 2782/2004; RJ 2006, 3108) y de 10 de noviembre de 2009 (Rec. 2745/2008; RJ 2010, 246).

12 STS de 14 de julio de 2016 (Rec. 161/2015; RJ 2016, 3407).
} 
los arts. 75.7 TRLET y 27.4 Ley 9/1987), «hace imposible con carácter previo la intervención de las partes para determinar la validez o no de la denegación, que tiene lugar mediante la correspondiente resolución administrativa» (LÓPEZ FERNÁNDEZ, 1994: 568).

Esa y no otra ha de ser la conclusión, puesto que, a mayor abundamiento, si el legislador hubiera querido establecer ese mecanismo potestativo y alternativo -acudir al arbitraje o presentar directamente la reclamación judicial- de impugnación contra las denegaciones de inscripción o registro de un acta por la Oficina Pública se hubiese expresado, en los artículos 76.1 TRLET y 44.f) TREBEP, en los mismos términos que lo hizo con motivo de la nueva regulación de las elecciones a órganos de representación del personal al servicio de la Administración General del Estado, respecto de las cuales estableció que «en las reclamaciones contra denegaciones de inscripción podrá optarse entre la promoción de dicho arbitraje o el planteamiento directo de la impugnación ante la Jurisdicción Social» (art. 28.1 Ley 9/1987). Actualmente, la redacción del 44.f) TREBEP, que se mantiene desde la aprobación de la Ley 7/2007, de 12 de abril, del Estatuto Básico del Empleado Público, viene a corroborar aquella interpretación, al contradecir lo dispuesto en la norma anteriormente vigente y reflejar -literal- lo dispuesto en la legislación laboral, ya desde la reforma de 1994. En fin, de haber querido preservar dicha alternativa, se hubiera conservado la misma redacción, siendo claramente otra la voluntas legislatoris ${ }^{13}$.

\subsubsection{Iniciación, desarrollo y finalización: del escrito de impugnación al laudo arbitral}

El procedimiento arbitral legalmente establecido podrá promoverse por todos los que tengan interés legítimo en un determinado proceso electoral, incluida la empresa o la Administración Pública afectada cuando en ellas concurra dicho interés. Pueden impugnarse todas las actuaciones o decisiones de la Mesa Electoral, inclusive los actos previos a la constitución de la misma inicialmente dotados de eficacia jurídica y la atribución de resultados. De impugnar actos propios de la Mesa Electoral, como requisito o exigencia legal, se debe acreditar haber efectuado previamente reclamación ante la misma, dentro del día siguiente laborable al acto que motiva la impugnación.

El fundamento de la impugnación será la existencia de vicios graves que puedan afectar a las garantías del proceso electoral y que alteren sus resultados, la falta de capacidad o legitimidad de los candidatos elegidos, la discordancia entre el acta y el desarrollo del proceso electoral o la falta de correlación entre el número de trabajadores que figuran en el acta de elecciones y el número de representantes elegidos (arts. 76.2 TRLET y 28.2 Ley 9/1987). Ciertamente, las tres últimas causas de impugnación enumeradas podrían subsumirse en la primera -existencia de vicios graves que puedan afectar a las garantías del proceso electoral y que alteren sus resultados- por su amplitud (LÓPEZ FERNÁNDEZ, 1994: 569-570), aunque de esa forma se identifican de manera precisa algunos de los vicios que denotan mayor gravedad.

Con carácter previo se mantiene la obligatoriedad de formular la reclamación ante la Mesa Electoral dentro del día laborable siguiente al acto o decisión que motiva la impugnación. Se exceptúa, lógicamente, de dicha reclamación las impugnaciones que tengan por objeto actuaciones anteriores a la constitución de la Mesa Electoral, como la convocatoria o el preaviso de elecciones, o los actos del día de la votación o posteriores, puesto que la actuación de la Mesa concluye con la redacción y remisión del acta de escrutinio, por lo que no podrá resolverlos.

En todo caso, la reclamación previa deberá ser resuelta por la Mesa Electoral en el posterior día hábil, exceptuando el supuesto de empresas con menos de treinta trabajadores, en las que se elige un delegado de personal, en cuyo caso la Mesa resolverá en la misma acta de escrutinio (arts. 74.2, último párrafo, TRLET y 26.2, último párrafo, Ley 9/1987). Solamente en el caso de que la Mesa no hubiera resuelto la reclamación dentro de los plazos fijados, se entenderá que se trata de un acto presunto de carácter desestimatorio, a los efectos de iniciar el procedimiento arbitral (arts. 30.3 RD 1844/1994 y 25.3 RD 1846/1994). El legislador, por lo tanto, se decanta por otorgar valor negativo al silencio de la Mesa ante la reclamación previa presentada por cualquiera de los sujetos legitimados.

13 No se desconoce que la disposición transitoria quinta, primero, de la Ley 7/2007, de 12 de abril, del Estatuto Básico del Empleado Público y, después, del TREBEP, aunque derogó Ley 9/1987, excepto su artículo 7, y estableció que mantiene aplicable el artículo 28 , entre otros preceptos, con carácter de norma básica, «en tanto se determine el procedimiento electoral general previsto en el artículo 39 del presente Estatuto», si bien, en este punto concreto y por contradecir lo dispuesto en la nueva ley en vigor, ha de aplicarse esta última porque, como establece la legislación común, la derogación tiene el alcance que expresamente se dispone y se extiende siempre a todo aquello que en la ley nueva, sobre la misma materia, sea incompatible -lex posterior derogat priori- con la anterior (art. 2.2 Código Civil) 
El procedimiento arbitral se inicia mediante escrito dirigido a la Oficina Pública competente, según el ámbito territorial del proceso electoral impugnado. En el escrito impugnatorio deben figurar obligatoriamente los siguientes datos (arts. 37 RD 1844/1994 y 32 RD 1846/1994):

- La Oficina Pública competente a la que se presenta la impugnación electoral, si bien el error en la determinación de la misma no será impedimento para la tramitación del escrito impugnatorio.

- La identificación -nombre, apellidos, Documento Nacional de Identidad y, en su caso, acreditación de su representación- y el domicilio del promotor de la reclamación.

- La identificación y domicilio de las partes afectadas por la impugnación del proceso electoral.

- Los hechos motivadores de la reclamación, que obligatoriamente será alguno de los previstos legal y reglamentariamente.

- La acreditación de haber efectuado la reclamación previa, en tiempo y forma, ante la Mesa Electoral, cuando ser trate de impugnación de actos llevados a cabo por la misma.

- La solicitud de acogerse al procedimiento arbitral previsto en el artículo 76 TRLET o en el artículo 44.f) TREBEP.

- El lugar, la fecha y firma del promotor de la reclamación.

El contenido mínimo del escrito de impugnación no incluye una exposición de los fundamentos jurídicos que se consideran de aplicación, pero sí es conveniente puesto que el árbitro debe resolver en derecho (arts. 76.6 TRLET y 29.3 Ley $9 / 1987$ ).

El escrito dirigido a la Oficina Pública podrá presentarse directamente en el registro de dicho organismo, así como en los registros de cualquier otro órgano administrativo - de la Administración General del Estado, de la Administración de una Comunidad Autónoma, de las entidades que integran la Administración Local e incluso del sector público institucional-y en las oficinas de Correos, en la forma reglamentariamente establecida (art. 16.4 Ley 39/2015, de 1 de octubre, del Procedimiento Administrativo Común de las Administraciones Públicas). Si bien el procedimiento arbitral que se sigue no es un procedimiento administrativo, no podemos olvidar que la Ley establece, literalmente, que el inicio del procedimiento arbitral se solicitará mediante escrito dirigido a la Oficina Pública y que dicha oficina está integrada en la Administración Pública estatal o autonómica, dependiendo de las competencias transferidas, por lo que resulta de aplicación lo dispuesto en el precepto citado, en cuanto al registro de solicitudes, escritos y comunicaciones que los ciudadanos dirijan a los órganos de la Administración ${ }^{14}$.

Como regla general, se establece un plazo de tres días para instar el inicio del procedimiento arbitral, contados desde el día siguiente a aquel en que se hubieran producido los hechos o resuelto la reclamación por la Mesa. No obstante, si quienes promueven el procedimiento arbitral son sindicatos que no han presentado candidatura, los tres días se computarán desde que se conozca el hecho impugnable. Esta última previsión plantea la dificultad de probar la fecha en que se ha tenido conocimiento del hecho impugnado; más aún, puede acarrear inseguridad jurídica porque, siendo sindicatos que no han participado activamente en el proceso electoral, el conocimiento de la irregularidad puede retrasarse en el tiempo, siendo factible 0 quedando abierta su impugnación.

Aquel plazo común de impugnación tiene una importante excepción: el plazo para iniciar el procedimiento arbitral será de diez días hábiles, contados a partir de la entrada de las actas en la Oficina Pública dependiente de la Autoridad laboral, cuando se trate de impugnar actos del día de la votación o posteriores al mismo (arts. 76.5 TRLET y 29.1 Ley 9/1987). La impugnación del acta o de otros actos simultáneos o posteriores al día de la votación goza de un plazo ampliado para su impugnación, plazo que coincide con el de exposición pública de las actas en la Oficina Pública hasta su registro (arts. 75.6 TRLET y 27.3 Ley 9/1987). Al tratarse el último supuesto de una excepción al plazo general de tres días hábiles, conviene distinguir, a efectos de determinar los plazos de impugnación, entre los actos del día de la votación y posteriores, de una parte, y aquellos actos que son conocidos por medio del acta de escrutinio, pero que no son actos del día de la votación ${ }^{15}$, de otra. En este último caso, y siempre que se trate de un sindicato que no ha presentado candidatura en el proceso electoral seguido, se aplicará el plazo de tres días hábiles desde su conocimiento

${ }_{14}$ Así se ha aceptado por la Sentencia del Juzgado de lo Social núm. 6 de Zaragoza, de 6 de marzo de 1995 (núm. 130/1995), relativa a la presentación del escrito de solicitud de inicio del procedimiento arbitral en la Delegación del Gobierno.

15 Por ejemplo, la determinación irregular del número de representantes a elegir que es conocida por un sindicato que no ha presentado candidatura en ese proceso electoral y que, por tanto, no ha participado en él; conocerá dicha irregularidad cuando se registren las actas electorales. 
-el registro del acta electoral- y no el de diez días hábiles que corresponde a la impugnación de los actos de día de la votación.

En todo caso, el planteamiento del arbitraje interrumpe los plazos de prescripción, a la vez que impide la tramitación de un nuevo procedimiento arbitral hasta que el primero no finalice, incluyendo en su caso la posterior impugnación judicial del laudo, y todo ello con la finalidad de evitar pronunciamientos contradictorios, dotados de eficacia jurídica. Aunque nada dice ex lege, la brevedad de los plazos de tramitación, que a continuación se enumeran, conlleva la no paralización del proceso electoral, puesto que así se deduce de lo establecido en el artículo 132.1.c) LRJS para el inmediato proceso judicial de impugnación del laudo. En efecto, solo se reconoce al Juez de lo Social, previa petición de la parte basada en justa causa, la paralización del procedimiento electoral. El árbitro, por su parte, no puede hacer uso de esta facultad, aunque nada impide que la existencia de una impugnación pueda ser tomada en cuenta por la Mesa Electoral, dentro de su función de señalar los plazos electorales «con criterios de razonabilidad y según lo aconsejen las circunstancias» (arts. 74.2 TRLET y 26.2 Ley 9/1987).

Recibido el escrito de impugnación, la Oficina Pública competente dará traslado del mismo, junto con una copia del expediente administrativo electoral, al árbitro en el día siguiente hábil, suspendiendo el registro de las actas electorales, de haberse presentado, en tanto se resuelva definitivamente el procedimiento arbitral.

El árbitro convocará a las partes interesadas, en las veinticuatro horas siguientes, para que comparezcan ante él, lo que tendrá lugar dentro de los tres días hábiles posteriores. Antes de la comparecencia, y durante ese periodo previo, las partes pueden ponerse de acuerdo para designar otro árbitro, notificándolo a la Oficina Pública para que dé traslado al nuevo árbitro del expediente, a los efectos de que continúe el resto del procedimiento.

En el mismo acto de comparecencia, o incluso con anterioridad, cabe plantear la posibilidad de desistimiento ${ }^{16}$ por la parte actora. Parece lógico pensar que el desistimiento ocasionará la terminación (NICOLÁS FRANCO, 1994: 22, y RODRÍGUEZ RAMOS; PÉREZ BORREGO, 2002: 244) del procedimiento arbitral porque en este rige el principio dispositivo y la instancia arbitral solo puede actuar de oficio para impulsar el procedimiento. Ahora bien, una vez iniciado el trámite arbitral y citadas las partes a la comparecencia deberá celebrarse la misma, dictando el árbitro el laudo correspondiente, pues de lo contrario podría lesionarse la expectativa de cualquier parte interesada que teniendo conocimiento de la impugnación registrada no presentó la suya a la espera de alegar y proponer las pruebas que considere oportunas, además de evitar así la posibilidad de transacciones durante ese tiempo entre los distintos sindicatos y la empresa. Si se diera por finalizado, sin más actuaciones, el procedimiento y no se dictara laudo alguno, se privaría la expectativa de tutela judicial, al no poder impugnar tampoco el laudo posterior. En suma, únicamente en el caso de no oponerse ninguna de las partes presentes en la comparecencia, el árbitro dará por concluido el procedimiento arbitral impugnatorio. Por los mismos motivos, el árbitro no está obligado a aceptar el posible acuerdo que surja entre las partes, si no comparte el contenido del mismo, puesto que está obligado a resolver en derecho.

Una vez oídas las partes en el acto de comparecencia ${ }^{17}$ y practicadas, de oficio o a instancia de parte, las pruebas procedentes, que podrá incluir la personación en el centro de trabajo y la solicitud de la colaboración necesaria del empresario o de la Administración Pública afectada, así como de cualesquiera otras instancias administrativas, el árbitro dictará el correspondiente laudo dentro de los tres días siguientes a la comparecencia. No obstante, aunque no se diga por las leyes ni tampoco por las normas reglamentarias de desarrollo, dicho plazo final se suspenderá si las pruebas solicitadas al empresario o a la Administración Pública no se han recibido por el árbitro en ese periodo. El laudo deberá ser escrito y razonado ${ }^{18}$, resolviendo en derecho sobre la impugnación del proceso electoral y, en su caso, sobre el registro de las actas ${ }^{19}$; con

16 Los mismos efectos que el desistimiento debe producir la incomparecencia o la comparecencia sin acreditar la representación necesaria (Sentencia del Juzgado de lo Social núm. 4 de Zaragoza, de 10 de febrero de 1995).

17 Se ha criticado (FALGUERA BARÓ, 1994: 324-325) con acierto, desde un perspectiva estrictamente procesal y formalista, que el legislador no haya establecido expresamente mayores requisitos garantistas del acto de comparecencia.

18 A pesar de que se dice únicamente que el laudo será escrito y razonado, sin ninguna otra especificación sobre su contenido, parece oportuno que en él se identifiquen las partes que han concurrido en el proceso arbitral, la cuestión o las cuestiones impugnadas, las alegaciones y pruebas practicadas, así como la correspondiente fundamentación jurídica en la que se basa la decisión arbitral, con la advertencia de que en el plazo de tres días desde su notificación se podrá impugnar el laudo ante la jurisdicción social.

19 Puede darse el caso de impugnar un hecho del día de la votación, o sucedido en días posteriores, y que las actas ya se hubieran presentado para su registro. Dicho registro quedará en suspenso durante la tramitación del arbitraje, decidiendo finalmente el laudo sobre su registro. 
ello se está exigiendo, dicho con otras palabras, que el laudo sea una resolución suficientemente motivada y congruente con la petición de parte. Caso de haberse impugnado la votación, la Oficina Pública, conocido el sentido de la resolución arbitral, procederá al registro de las actas o a su denegación.

Se notificará una copia del laudo a las partes interesadas y a la Oficina Pública dependiente de la Autoridad laboral, competente en materia electoral, con la advertencia de que contra el mismo se podrá interponer recurso ante el orden jurisdiccional social, en el plazo de tres días, contados desde que se tuvo conocimiento del laudo (arts. 76.6 TRLET, 29.3 Ley 9/1987 y 127.3 LRJS). Con todo, la eficacia y efectividad del laudo arbitral queda garantizada aun en el caso de que no se impugne ante la jurisdicción social, a través de la modalidad procesal correspondiente, por cuanto la Oficina Pública está vinculada por la decisión arbitral (BLASCO PELLICER, 1994: 94).

\subsection{La impugnación judicial de los laudos arbitrales}

El laudo con el que finaliza el procedimiento arbitral puede impugnarse ante la jurisdicción social, por la modalidad procesal prevista en los artículos 127 a 132 LRJS, que establecen un procedimiento urgente, en el que podrán actuar aquellos que tengan interés legítimo, incluida la empresa o la Administración Pública afectada, cuando en ellas concurra dicho interés.

El legislador condiciona esta acción a un breve plazo de caducidad, tres días desde que se tuvo conocimiento del laudo arbitral, periodo excesivamente corto si consideramos que el laudo lo pueden impugnar, también, quienes no fueron parte en el procedimiento arbitral (ALFONSO MELLADO, CARRATALÁ TERUEL y MORRO LÓPEZ, 1994: 6) y, por consiguiente, no se les notificó el laudo. La posibilidad de impugnación por quien no fue parte en el procedimiento arbitral puede acarrear, por consiguiente, problemas respecto de la acreditación de la fecha en que se ha tenido conocimiento del laudo ${ }^{20}$, creándose así cierta inseguridad jurídica.

La demanda preceptivamente se debe dirigir contra las personas y sindicatos que fueron parte en el procedimiento arbitral de referencia, así como frente a cualquier otro afectado por el laudo objeto de impugnación. Al respecto, se excluyen de la condición de demandados a los delegados de personal, a los comités de empresa y a las juntas de personal, según sea el ámbito electoral, e igualmente a la Mesa Electoral, incluso cuando se impugnen actos de ella misma. La exclusión de esta última como demandada parece discutible (LÓPEZ FERNÁNDEZ, 1994: 577), si bien el Tribunal Constitucional ha entendido que «la Mesa Electoral no es más que una institución de servicio cuya actividad se limita a regir la elección, quedando, en consecuencia, al margen de los derechos que en ella (la impugnación) se cuestionen. De este modo, la Mesa Electoral no es titular de ningún interés respecto del resultado de las elecciones sindicales» ${ }^{21}$.

No obstante, la existencia de legitimación pasiva será examinada de oficio por el Letrado de la Administración de Justicia del órgano judicial que vaya a conocer de la demanda de impugnación del laudo arbitral. De advertir errores en la constitución de la relación jurídico-procesal, por no haber sido dirigida contra todos los afectados, citará a las partes a una audiencia preliminar, dentro del día siguiente, en la que, oyendo a todas las partes sobre la posible situación de litisconsorcio pasivo necesario, resolverá lo que proceda en el mismo acto. Se trata, en fin, de subsanar este defecto procesal para evitar posibles indefensiones que llevarían a la nulidad del proceso seguido.

Asimismo, superando las reglas señaladas sobre la correcta constitución de la relación jurídico-procesal desde la óptica de la legitimación activa y pasiva, podrán comparecer como partes, aunque no hubieran sido demandados, los sindicatos, el empresario o la Administración Pública afectada y los componentes de candidaturas no presentadas por sindicatos, si tuvieran interés legítimo. No se trata ya de un mandato preceptivo, como la revisión de la demanda por el Letrado de la Administración de Justicia, sino de una posibilidad que se brinda a estos sujetos para ser oídos en el acto del juicio.

Lo transcendente, empero, de la impugnación judicial del laudo arbitral reside en las circunstancias o hechos que pueden motivar la misma. A estos efectos, la demanda «solo» podrá fundarse en: a) la indebida apreciación o no apreciación de cualquiera de las causas contempladas ex lege (arts. 76.2 TRLET y 29.2 Ley $9 / 1987$ ), siempre que hubieran sido alegadas por el promotor en el curso del arbitraje; b) haber resuelto

20 Quien pretenda oponer la caducidad deberá probar la fecha de conocimiento del laudo por el impugnante, cuestión esta de difícil prueba si quien reclama es alguien al que no se le ha notificado el laudo (ALBIOL MONTESINOS, 1995: 16).

21 AATC 209/1991 y 210/1991, de 2 de julio. 
el laudo aspectos no sometidos al arbitraje o que, de haberlo sido, no puedan ser objeto del mismo ${ }^{22}$; c) la promoción del arbitraje fuera de los plazos estipulados; o, d) no haber concedido el árbitro a las partes la oportunidad de ser oídas o de presentar pruebas ${ }^{23}$ (art. 128 LRJS).

El combate judicial del laudo es, como fácilmente se comprueba, omnicomprensivo (RíOS SALMERÓN, 1994: 424). Puede impugnarse el laudo por defectos formales, tales como el promover el arbitraje transcurrido el plazo legal o no respetar los principios de audiencia y contradicción, y por cuestiones de fondo, lo que permite calificar a la vía judicial como una auténtica segunda instancia ya que permite analizar aspectos sustantivos que fueron resueltos por el árbitro (RUIZ MORENO, 1994: 711). Aunque aparentemente el legislador creó un recurso extraordinario (MARÍN CORREA, 1995, 172) con motivos tasados, estos son tan amplios que permiten una auténtica revisión, tanto de la forma como del fondo, del proceso arbitral de instancia. Ahora bien, la revisión de fondo del laudo arbitral no se puede hacer sobre la base de una cuestión nueva a resolver por el Juez, sino solamente sobre la temática ya planteada por el promotor en el curso del arbitraje ${ }^{24}$ o, incluso, determinada antes en el escrito de reclamación ante la Mesa Electoral, por eso la impugnación se basará en la no apreciación o en la apreciación indebida por el árbitro de la causa correspondiente.

Al admitir la demanda, desde el Juzgado de lo Social competente ${ }^{25}$ se recabará de la Oficina Pública una copia del expediente administrativo relativo al proceso electoral, que en todo caso incluirá el texto del laudo objeto de impugnación. Como este proceso es calificado por el legislador de urgente, la documentación citada debe ser enviada por el requerido dentro del día siguiente, el acto del juicio se debe celebrar dentro de los cinco días siguientes a la admisión de la demanda y la sentencia tendrá que dictarse en el plazo de tres días. Quizá por tratarse de un proceso tramitado con urgencia, la demanda está exenta de los requisitos de conciliación o mediación previa (art. 64.1 LRJS), sin admitir tampoco acumulaciones (art. 26.1 LRJS).

La sentencia que resuelva la impugnación del laudo solo podrá confirmar o revocar, de forma total o parcial, la decisión arbitral de nulidad o pronunciarse sobre la validez del procedimiento electoral seguido en la concreta unidad electoral, además de imponer al empleador una sanción cuando aprecie que presentó la demanda para obstaculizar o retrasar el procedimiento electoral, es decir, cuando observe temeridad en la impugnación empresarial. De estimar cualquiera de los motivos señalados en el artículo 128 LRJS, debe anular el procedimiento arbitral, resolviendo sobre el fondo y, en su caso, ordenando reponer el procedimiento arbitral al momento en que se produjo la correspondiente falta procedimental, a los efectos de que se repita el procedimiento observando todas las garantías. Se exceptúa de esta regla general el supuesto de pronunciamiento ultra vires del arbitro cuando los aspectos no sometidos a arbitraje o no susceptibles del mismo «tengan sustantividad propia y no aparezcan indisolublemente unidos a la cuestión principal» [art. 128.b) LRJS].

En todo caso, independientemente del sentido del fallo, el Juez deberá comunicar la sentencia a las partes y a la Oficina Pública. La obligada notificación del contenido de la sentencia a ese órgano administrativo, que no ha sido parte en el proceso judicial, tiene su justificación por ser el órgano competente para registrar las actas electorales, pues no debemos olvidar que la impugnación judicial no suspende el desarrollo del procedimiento electoral, a no ser que el Juez lo decida a petición justificada de parte.

Por último, hay que subrayar que contra la sentencia no cabe recurso [art. 132.1.b) LRJS], «aunque, con seguridad, cabe el de suplicación que tenga por objeto subsanar una falta esencial de procedimiento que haya producido indefensión y que haya sido protestada» (RíOS SALMERÓN, 1994: 424), conforme al artículo 191.3.d) LRJS.

22 Conforme a esta causa, cabe la impugnación del laudo por decisión ultra vires del árbitro, al haberse excedido sobre la materia que las partes sometieron a arbitraje o haber resuelto sobre vicios en el proceso electoral no contemplados en el artículo 76.2 TRLET -o también en el art. 29.2 Ley 9/1987-o sobre materias no electorales.

23 En el supuesto de haberse ignorado como parte a algún legitimado que debiera ser oído preceptivamente, o aun teniéndole como parte no se hubiera respetado sus derechos de alegación y prueba, cabe la impugnación del laudo por no respetar los principios de audiencia y contradicción (RUIZ MORENO, 1994: 716-718).

${ }^{24}$ Es el escrito de promoción del arbitraje presentado en su momento el que, principalmente, fijará los términos del debate en la impugnación judicial del laudo.

25 En los procesos electorales será competente el Juzgado de lo Social del lugar en cuya circunscripción esté situada la empresa o centro de trabajo; y si los centros están situados en municipios distintos, en que ejerzan jurisdicción Juzgados diferentes, con unidad de comité de empresa o de órgano de representación del personal al servicio de las Administraciones públicas, el del lugar en que inicialmente se había constituido la Mesa Electoral [art. 10.2.g) LRJS]. 


\section{A MODO DE CONCLUSIÓN: TRANSCENDENCIA DEL PROCESO ELECTORAL Y RESOLUCIÓN EXTRAJUDICIAL DE LOS CONFLICTOS JURÍDICOS}

Se justifica este trabajo, superando la materia singular objeto de análisis, por la doble la función de las -así llamadas- elecciones sindicales (PALOMEQUE LÓPEZ, 1994: 207), y ello porque sirven para elegir a los representantes del personal al servicio de una Administración Pública, que se pueda identificar como unidad electoral, al mismo tiempo que los resultados obtenidos por cada sindicato en las elecciones a los órganos de representación unitaria o electiva de los trabajadores y funcionarios, esto es, la audiencia electoral (NAVARRO NIETO, 1993: 206 y ss.), se toman para determinar en nuestro ordenamiento la denominada «mayor representatividad» y la «mera o suficiente representatividad» de los sindicatos ${ }^{26}$. Dicho con otras palabras, además de la elección de los representantes unitarios o legales, las elecciones sindicales tienen la finalidad institucional de constatar oficialmente el quantum de representatividad de los distintos sindicatos, cualquiera que sea su forma de organizarse, a lo que la ley anuda importantes consecuencias, entre otras la de representar los intereses del personal en entidades y organismos públicos ${ }^{27}$. La importancia y significación de esta segunda función -la medición de la representatividad sindical-, que deriva de los resultados de los procesos electorales, distorsiona (NICOLÁS FRANCO, 1994: 9) la propia finalidad de la representación de los trabajadores y funcionarios y aleja el objetivo de alcanzar un equilibrio necesario entre ambas funciones.

No es de extrañar que, tras el pacto previo de los sindicatos estatales mayoritarios -UGT y CC.OO-, que en septiembre de 1992 acordaron una «Propuesta de modificación de la normativa electoral y la representatividad sindical» ${ }^{28}$, el legislador reformista de 1994 introdujera uno de los cambios normativos de mayor significación: el régimen de elección de los representantes unitarios o legales de los trabajadores y funcionarios.

Las leyes de reforma, aceptando la validez social del método de medición de la representatividad sindical por la audiencia electoral, modificaron el sistema electoral ante la existencia de problemas prácticos derivados, fundamentalmente, de la concentración de los procesos electorales en un periodo limitado de tiempo, entre los que se mencionaba reiteradamente la innecesaria, por excesiva, confrontación entre las distintas opciones sindicales, así como, también, la gran litigiosidad en el control del cómputo de los resultados electorales; situaciones que, además de dificultar la obtención de datos fiables para medir la representatividad, trasladaban a la sociedad una imagen negativa de la actuación de los interlocutores sociales y de la Administración laboral. Por esos motivos se sustituyó el sistema cerrado de cómputo de resultados electorales por otro abierto en el tiempo, evitando la proclamación global de los resultados y la actuación de los anteriores órganos tripartitos; a cambio, se implantó un sistema de registro administrativo para acreditar la representatividad, según los resultados vigentes en el momento en que, en cada caso, deban ejercerse las funciones representativas. La reforma en esta materia se completó con nuevas reglas sobre promoción de elecciones, celebración de estas o funciones de la Mesa Electoral, a la vez que se crearon nuevas figuras e instituciones jurídicas, como la Oficina Pública de registro de actas, y -lo que fue más novedoso- un procedimiento de reclamación en materia electoral, que sustituía la actuación de los órganos tripartitos por un procedimiento arbitral, dotado de las suficientes garantías en cuanto a la ulterior tutela judicial.

Entre todas las modificaciones enumeradas, interesa subrayar la referida a las reclamaciones en materia electoral. Tras la reforma de 1994, la actuación de la Oficina Pública dependiente de la Autoridad laboral queda limitada al registro de las actas de escrutinio o denegación del mismo, excluyendo su intervención en cualquier tipo de control sobre la validez del proceso electoral. En verdad, se introdujo un sistema extrajudicial de solución de conflictos electorales (BLASCO PELLICER, 1994: 92), para reducir el elevado número de controversias judiciales surgidas en anteriores convocatorias, sin perjuicio, no obstante, del posible control judicial posterior (MATÍA PRIM, 1994: 230).

En efecto, que el legislador haya establecido un sistema extrajudicial de solución de controversias electorales obligatorio no impide el control de validez del proceso electoral puesto que es posible acudir a la ju-

${ }^{26}$ Cfr. Artículos 6 y 7 de la Ley Orgánica 11/1985, de 2 de agosto, de libertad sindical (en adelante, LOLS).

27 STC 7/1990, de 18 de enero (BOE de 15 de febrero de 1990).

28 Ante la excesiva politización y las disfuncionalidades observadas se convino en la necesidad de revisar en profundidad la normativa electoral. Así surgió el acuerdo entre los sindicatos UGT y CC.OO, llegando a convertirse su propuesta, con alguna variación parcial, en "Anteproyecto de Ley de modificación de la normativa de elecciones sindicales". Finalmente, ante la presentación al Consejo Económico y Social de España de un nuevo "Anteproyecto de Ley por el que se modifican determinados artículos de la Ley 8/1980, de 10 de marzo, del Estatuto de los Trabajadores", este recomendó al Gobierno la unificación y discusión coordinada de los diversos textos que abordan la reforma laboral. 
risdicción social, bien directamente cuando se impugne la resolución administrativa que deniegue el registro de las actas electorales, bien indirectamente a través del recurso contra el laudo arbitral, que permite revisar el contenido del mismo.

El conjunto de actuaciones que tienen lugar a lo largo del itinerario electoral, desde la promoción hasta el registro y cómputo del resultado, ya provengan de la Mesa Electoral, ya de terceros interesados en la elección, goza de presunción de validez, de manera que mientras no se impugne alguno de los hechos o actos del trámite electoral, dentro del plazo de caducidad legalmente establecido, estos surten plenos efectos jurídicos. La no impugnación en tiempo y forma convalida los vicios o defectos en los que se hubiera incurrido en el decurso de cada elección. En caso contrario, la reclamación por parte de quien o quienes acrediten interés legítimo abre las vías de control en materia electoral. Y ello porque tanto la instancia arbitral como la judicial solamente pueden actuar de oficio para impulsar el procedimiento impugnatorio.

El procedimiento arbitral, diseñado ex lege y de obligada tramitación, aparece como una instancia previa a la judicial. Ahora bien, el laudo arbitral, fundado en derecho, debe resolver la reclamación planteada y puede ser impugnado ante los órganos de la jurisdicción social, tanto por razones formales como por motivos de fondo o materiales, con lo que se permite revisar, en realidad, la totalidad del contenido del laudo.

\section{REFERENCIAS BIBLIOGRÁFICAS}

ALBIOL MONTESINOS, I. (1995): "El proceso en materia electoral", en Tribuna Social, núm. 50.

ALFONSO MELLADO, C. L., CARRATALÁ TERUEL, J. L., MORRO LÓPEZ, J. J. (1994): La reforma del proceso laboral. Valencia: Tirant lo Blanch.

ALONSO OLEA, M., ALONSO GARCÍA, M. ${ }^{a}$ R. (2010): Derecho Procesal del Trabajo, 16. ${ }^{a}$ ed., Madrid: Civitas.

BAYLOS GRAU, A., CRUZ VILLALON, J., FERNÁNDEZ LÓPEZ, M. ${ }^{a}$ F. (1991): Instituciones de Derecho Procesal Laboral. Madrid: Trotta.

BLASCO PELLICER, C. (1994): "La reforma del proceso de elección y mandato de los representantes de los trabajadores en la empresa", en Tribuna Social, núm. 43.

CABEZA PEREIRO, J. (2009): Las elecciones sindicales. Albacete: Bomarzo.

CALVO GALLEGO, F. J. (1997): El arbitraje en las elecciones «sindicales». Valencia: Tirant lo Blanch.

CASAS BAAMONDE, M. ${ }^{a}$ E. (1994): "Arbitraje laboral, autonomía colectiva y autonomía individual", en Relaciones Laborales, núm. 2.

CC. OO. (2014): Elecciones sindicales: sentencias y laudos arbitrales, 2. ${ }^{\text {a }}$ ed., Albacete: Bomarzo.

DE VAL TENA, A. L. (1995): "El nuevo procedimiento de impugnación en materia electoral”, en Actualidad Laboral, núm. 38.

ESCUDERO RODRÍGUEZ, R. (1995): "El lugar de los sindicatos en la nueva regulación de las elecciones a representantes de los trabajadores y funcionarios públicos", en AA.VV.: Reforma de la legislación laboral. Estudios dedicados al Prof. M. Alonso García. Madrid: AEDTSS-Marcial Pons.

FALGUERA BARÓ, M. A. (1994): "La reforma del sistema de elecciones sindicales", en ALARCÓN CARACUEL, M. R. (coord.): La reforma laboral de 1994. Madrid: Marcial Pons.

LÓPEZ FERNÁNDEZ, M. (1994): "Reclamaciones en materia electoral", en VALDES DAL-RÉ, F. (dir.): La reforma del mercado de trabajo. Valladolid: Ed. Lex Nova.

MARÍN CORREA, J. M. a (1995): "Modificaciones introducidas en la Ley de Procedimiento Laboral", en BORRAJO DACRUZ, E. (coord.): El nuevo Estatuto de los Trabajadores: puntos críticos. Madrid: Actualidad Editorial.

MATÍA PRIM, J. (1994): "Las elecciones en la empresa", en Relaciones Laborales, núm. 17-18.

MEJÍAS, A. (2016): Elecciones sindicales: el preaviso electoral. Valencia: Tirant lo Blanch.

MONGE RECALDE. J. L. (1994): Comentarios a la reforma laboral de 1994. Barcelona: Ed. Bosch.

NAVARRO NIETO, F. (1993): La representatividad sindical. Madrid: Servicio de Publicaciones del Ministerio de Trabajo y Seguridad Social.

NICOLÁS FRANCO, A. (1994): "Apuntes sobre la reforma de la normativa reguladora de las elecciones sindicales", en Aranzadi Social, núm. 29.

PALOMEQUE LÓPEZ, M. C. (1994): Derecho sindical español, 5. ${ }^{\text {a }}$ ed., Madrid: Tecnos.

RíOS SALMERÓN, B. (1994): "Aspectos procesales de la reforma laboral de 1994", en Relaciones Laborales, núm. 2.

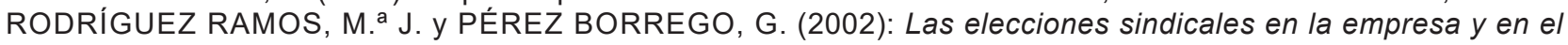
centro de trabajo. Cizur Menor (Navarra): Aranzadi.

RUIZ MORENO, J. M. ${ }^{a}$ (1994): "El nuevo procedimiento electoral sindical tras la Ley 11/1994, de 19 de mayo (Comentario a los artículos 127 a 136 LPL)", en Actualidad Laboral, núm. 46.

SEMPERE NAVARRO, A. V. (2015): "Elecciones sindicales y negociación colectiva en el sector público: nota al RDL 1/2015, de 27 febrero", en Revista Aranzadi Doctrinal, núm. 4. 